San Jose State University

SJSU ScholarWorks

Master's Theses

Master's Theses and Graduate Research

1992

\title{
The Effects of therapeutic touch on state anxiety and physiological measurements in preoperative clients
}

Diane Bowers

San Jose State University

Follow this and additional works at: https://scholarworks.sjsu.edu/etd_theses

\section{Recommended Citation}

Bowers, Diane, "The Effects of therapeutic touch on state anxiety and physiological measurements in preoperative clients" (1992). Master's Theses. 279.

DOI: https://doi.org/10.31979/etd.6s89-hqx2

https://scholarworks.sjsu.edu/etd_theses/279

This Thesis is brought to you for free and open access by the Master's Theses and Graduate Research at SJSU ScholarWorks. It has been accepted for inclusion in Master's Theses by an authorized administrator of SJSU ScholarWorks. For more information, please contact scholarworks@sjsu.edu. 


\section{INFORMATION TO USERS}

This manuscript has been reproduced from the microfilm master. UMI films the text directly from the original or copy submitted. Thus, some thesis and dissertation copies are in typewriter face, while others may be from any type of computer printer.

The quality of this reproduction is dependent upon the quality of the copy submitted. Broken or indistinct print, colored or poor quality illustrations and photographs, print bleedthrough, substandard margins, and improper alignment can adversely affect reproduction.

In the unlikely event that the author did not send UMI a complete manuscript and there are missing pages, these will be noted. Also, if unauthorized copyright material had to be removed, a note will indicate the deletion.

Oversize materials (e.g., maps, drawings, charts) are reproduced by sectioning the original, beginning at the upper left-hand corner and continuing from left to right in equal sections with small overlaps. Each original is also photographed in one exposure and is included in reduced form at the back of the book.

Photographs included in the original manuscript have been reproduced xerographically in this copy. Higher quality 6" x 9" black and white photographic prints are available for any photographs or illustrations appearing in this copy for an additional charge. Contact UMI directly to order.

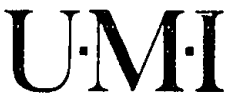

University Microfitms Internationa:

A Bell \& Howell Information Company

300 North Zeeb Road. Ann Arbor, MI 48106-1346 USA

$313 / 761-4700 \quad 800: 521.0600$ 

The effects of therapeutic touch on state anxiety and physiological measurements in preoperative clients

Bowers, Diane Patricia, M.S.

San Jose State University, 1992 

THE EFFECTS OF THERAPEUTIC TOUCH

ON STATE ANXIETY

AND PHYSIOLOGICAL MEASUREMENTS

IN PREOPERATIVE CLIENTS

\author{
A Thesis \\ Presented to \\ The Faculty of the Department of Nursing \\ San Jose State University \\ In Partial Fulfillment \\ of the Requirements for the Degree \\ Master of Science
}

\author{
By \\ Diane Bowers \\ May, 1992
}




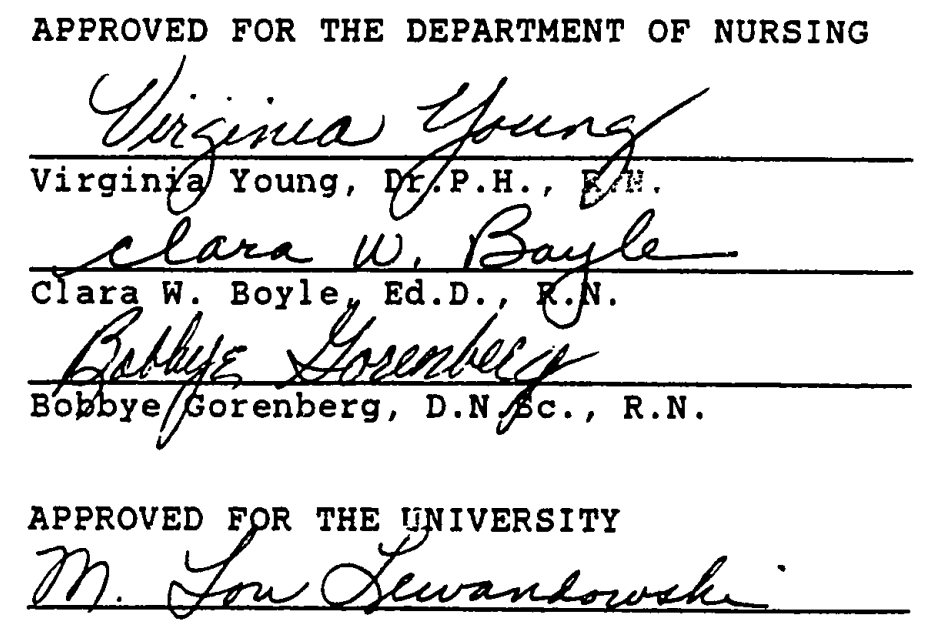


ABSTRACT

THE EFFECTS OF THERAPEUTIC TOUCH ON STATE ANXIETY AND PHYSIOLOGICAL MEASUREMENTS IN PREOPERATIVE CLIENTS

\section{by Diane Bowers}

This quasi-experimental pretest-posttest design study examined the effects of Therapeutic Touch and a mimic control treatment on measurements of blood pressure, heart rate, respiratory rate, peripheral skin temperature, and perceived feelings of anxiety in clients having surgery performed within 1 hour of hospital admission. The purpose of this study was to quantify the effects of Therapeutic Touch as a relaxation intervention. The STAI-Y state Anxiety questionnaire was used with 12 experimental group clients and 8 control group clients. Both groups experienced significant $(p<.05)$ positive changes in physiologic measurements and state anxiety indicative of relaxation. The hypotheses, however, were not supported. The degree of relaxation responses were not significantly greater is the expsimental group. Results of the Therapeutic Touch Practitioner Self-Inventory showed a positive correlation $(\underline{p}<.01)$ in the experimental group between clients' peripheral skin temperatures and the practitioner's perceived bonding with clients. 


\section{ACKNOWLEDGEMENTS}

To my graduate advisor, Dr. Virginia Young, for her wisdōin, guidance, support, endurance, and lifelong experience in the quest for excellence.

To Sharon Peters, whose enthusiasm, good nature, flexibility, and commitment made this study possible. Sharon was often the first smile at the break of dawn, even when situations were not laughable.

Special thanks to Dr. Clara Boyle, Dr. Bobbye Gorenberg, Sharon Hogan, and Geri Leeka. 
TABLE OF CONTENTS

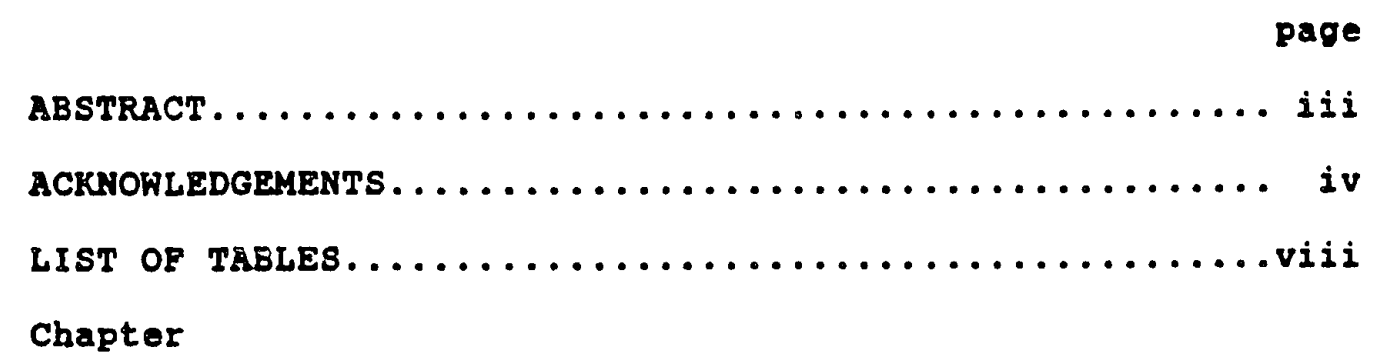

1. INTRODUCTION.......................... I

statement of the Problem................... 3

Purpose and Need...................... 5

objectives............................ 6

Hypotheses........................... 7

Definition of Terms..................... 7

significance of the study.................. s

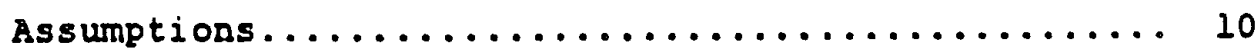

The Experiment...................... 11

Limitations........................ in

2. REVIEW OF CONCEPTUAL FRAMEWORK AND

RELATED LITERATURE................... 14

Concegtual Framework........................... 14

Therapeutic Touch Research: Related Literature..... 18

summary............................. 25 
3. RESEARCH DESIGN AND METHODOLOGY............. 26

Approval for the study.................. 26

sample and setting.................... 26

Methods of Data Collection................. 31

4. Results ANd data analysis................ 36

Results........................... 36

Within Group Measurements............... 37

Pretreatment variables................... 39

Differential variables................... 40

Therapeutic Touch Practitioner

Self-Inventory Results................ 42

The Hypotheses and Results............... 44

5. CONCLUSIONS AND RECOMMENDATIONS............. 45

Conelusions....................... 45

Recommendations.......................

Implications for Nursing Practice............ 51

REFERENCES. ......................... 55

ARPENDIXES.............................. 61

A. Client Questionnaire.................. 62

B. Approval by Human subjects Institutional

Review Board: San Jose State Uaiversity..... 64

c. nFFroval by Hospital Institutional

Review Committee................. 66 
page

D. Physician Consent....................668

E. Client Pre-Requisite Data Form............ 71

F. Client Consent and Experimental subject's

Bill of Rights................... 73

G. Therapeutic Touch Practitioner

self-Inventory................... 79

vii 


\section{LIST OF TABLES}

Table

page

1. Types of Participant surgical

Procedures......................... 30

2. Differences Between Pretreatment and

Posttreatment Measurements Within

the Control Group..................... 38

3. Differences Between Pretreatment and

Posttreatment Measurements Within

the Experimental Group................. 39

4. Control and Experimental Group Pretreatment

Heart Rate Measurements................ 40

5. Control and Experimental Group Respiratory

Rate Differential Values............... 42

6. Pearson Product-Moment Coefficient Correlation

of Perceived Bonding of Practitioner to Client

in Relationship to Keasured Differential

Variables During Therapeutic Touch........... 43 
Chapter 1

INTRODUCTION

Therapeutic Touch is based on the ancient healing practice known as laying-on of hands. It was first introduced to nursing by Dolores Krieger and Dora Kunz in 1975. Therapeutic Touch is a holistic healing modality which can be used by nurses as a complementary health-oriented intervention to potentiate the natural or self-healing process.

The art of nursing is expressed through intuitive and analytical skills used by nurses in helping, caring for, and nurturing those who are frail and ill. In a holistic framework, the nurse's role is to act as a healer, assisting clients in making connections between the body, mind, and spirit. The nurse healer is a guide who helps clients deal with the imbalances of disease, understand and make choices about new health behaviors, and discover insights about how to cope effectively.

Touching the client's hand or arm has been a traditional component of nursing care. Therapeutic Touch, as an expression of nurse-healing touch, is moze mentally focused and therefore requires a high level of intuitive assessment. Applying a holistic perspective, the healer uses the hands to explore and consciously redirect areas of 
perceived energy imbalance around the client's body. As with casual touch, the intent of Therapeutic Touch used by nurses is to relax, soothe and relieve physical, emotional, or spiritual discomfort.

The following is one case example demonstrating the effects of Therapeutic Touch. A man was admitted to the coronary care unit in a hospital with a diagnosis of myocardial infarction. The nurse caring for him on the day after admission assessed his general demeanor as anxious and withdrawn; he was having difficulty communicating with his family and the nursing staff. The nurse asked if she could perform a Therapeutic Touch intervention upon him. Following the intervention, the man began to cry as he expressed his deepest fears about his illness. He also told the nurse that he experienced great relief after the intervention. In this example, the mechanisms which permitted the man to release his feelings are not completely clear. One hypothesis is that the nurse's empathetic behavior combined with Therapeutic Touch as an adjunct measure served to assist the client in emotional self healing. Therapeutic Touch can help clients relax, reduce anxiety and fear; relieve the pain of musculoskeletal disorders, arthritis, and migraine headaches; and reduce the side effects of chemotherapy such as nausea. Additionally, Therapeutic Touch has been reported to lower blood pressure, 
decrease edema, ease abdominal cramps, and resolve fevers. When practiced consistently, Therapeutic Touch may produce feelings of relaxation, well-being, and increased energy in the therapist as well as the recipient (Boguslawski, 1980; Borelli \& Heidt, 1981; Krieger, 1979).

statement of the Problem

Two related concepts expiain how Therapeutic Tolich works, but little scientific evidence has been provided. The first concept is an Eastern philosophical system derived from Buddhism, Taoism, and Hinduism, which proposes that the universe is composed of energies that include an ultimate and unified source of existence, and through which all matter and consciousness are interconnected (Govinda, 1974). The prana, or human vitality energy, keeps the individual healthy (Govinda, 1974). During Therapeutic Touch, an excess of the nurse's prana energy can be transferred to the client whose flow is depleted, facilitating the healing process. The holistic health framework, developed during the $1970^{\prime}$ s, supports the Eastern philosophical view of the universe as an open system of energies.

The second concept is based on the nursing conceptual model of Martha Rogers (1970), which suggests that energy fields are the fundamental units of the individual and the environment. These energy fields interact in wave patterns. The intent of nursing practice is to preserve the integrity 
of human and environmental fields by redirecting patterns of energy and organization to restore maximum health.

Therapeutic Touch is a specific example of this concept. More recent studies have begun to provide evidence of the presence of a human electromagnetic field surrounding the body. These studies also describe changes which occur in the human field as a result of intentional healing actions by therapist healers (Hunt, 1988).

Another issue in Therapeutic Touch research which has varied significantly from study to study is the technique of physical contact versus non-physical contact by the practitioner. Early studies in Therapeutic Touch techniques used direct physical contact. Quinn (1984) and Keller and Bzdek (1986) demonstrated the effects of Therapeutic Touch without physical contact. Quinn questioned the significance of actual physical contact to achieve the desired effects of Therapeutic Touch. Since theoretical frameworks frum previous investigators had proposed that energy fields were open and unbounded (Rogers, 1970; Weber, 1981), Quinn (1984) hypothesized that energy exchange between the healer and client could be achieved without physical contact. Jurgens, Meehan, and Wilson (1988) suggest that the placebo effect and Therapeutic Touch may be aspects of the same phenomena, thus presenting additional controversy in explaining the origin of the positive outcomes of the 
treatment. Jurgens, Meehan, and Wilson define the placebo effect as (a) the fact that the treatment is being offered, (b) the subject's belief in the treatment and expectation of the effect, and (c) implicit and explicit suggestion by the individual administering the treatment.

Perhaps, then, the placebo effect cannot be eliminated completely when there is implicit and explicit suggestion by the nurse. If energy is universal and open, can intent of thought permit or block the flow of energy directed to the client? If the nurse blocks the flow of energy by intentionally concentrating on something else, will the client's desire and openness to healing allow the forces of natural or self-healing to occur anyway?

Quinn (1984) was the first to examine the effect of placebo Therapeutic Touch on human subjects by simulating Therapeutic Touch without intent to heal. Other studies have compared the effects of Therapeutic Touch with placebos such as casual touch, casual touch with verbal empathy (Heidt, 1980), and casual touch with patient teaching (Whitcher \& Fisher, 1979).

\section{Purpose and Need}

Continuing studies are needed to test the effects of Therapeutic Touch without physical contact, comparing the effects of placebo contact with intentional healing, and supporting the broader conceptual framework of energy 
exchange both between nurse and client, and between humans and their environment. The purpose of this study was to answer two questions:

1. What is the effect of Therapeutic Touch administered without physical contact on state anxiety of preoperative clients?

2. What is the effect of Therapeutic Touch administered without physical contact, on blood pressure, pulse rate, respirations, peripheral skin temperature, and electromyographic activity of preoperative clients?

\section{objectives}

This study examined the effects of energy exchange between a nurse healer and client through the subjective measures of pretest and posttest STAI-Y state Anxiety scores, and the objective measures of blood pressure, pulse rate, respiratory rate, peripheral skin temperature, and electromyographic activity. This study paralleled Quinn (1984) in hypotheses, treatment and control interventions, use of state anxiety instrument, and calculation of findings. While Quinn examined only the variable of state anxiety in a hospitalized patient population, this study measured both state anxiety and other physiological measures in hospitalized preoperative clients. 
Hypotheses

The formulated hypotheses were:

1. There will be a grealer decrease in posttest anxiety scores in preoperative clients treated with Therapeutic Touch without physical contact, than in the control group treated with the Noncontact treatment.

2. The total mean decrease in blood pressure, pulse rate, respiratory rate, electromyographic activity and the total mean increase in peripheral skin temperature will be greater in preoperative clients who have been treated with Therapeutic Touch without physical contact, than in the control group treated with the Noncontact treatment.

$$
\text { Definition of Terms }
$$

The following definitions were applied in this study:

1. Therapeutic Touch is a process that uses the hands if a healer to direct excess body energy from the client for the purpose of helping or healing the individual (Krieger, 1976).

2. Noncontact Therapeutic Touch (NCTT) is a 5 minute therapeutic intervention applied by the researcher made with intention to mentally assist the patient. Steps describing the procedure are found in the literature (Heidt, 1980; Krieger, 1979; Borelli \& Heidt, 1981). The practitioner:

(1) Made the intention mentally to assist the patient. 
(2) Used centering, a meditative state which allows the healer to become aware of herself as an open system of universal energies.

(3) Moved the hands over the body of the client from head to feet including the chakra energy channels, attuning to the condition of the subject by becoming aware of changes in sensory cues such as heat, coidness, tingling, density, or openness.

(4) Redirected the areas of accumulated energy away from the source in the client's body. This has been described as 'unruffling the field' (Borelli \& Heidt, 1981). (5) Concentrated on directing new healing energy into the crown chakra to replace removed energy from the body. This step was done in lieu of directing energy to the solar plexus, as described in other literature sources.

3. Contact Therapeutic Touch (CTT) as described by Heidt (1980), and Quinn (1984) follows the same steps as NCTT, except in one step the healer places hands directly on the solar plexus area (just above the waist) to direct energy to the client.

4. State Anxiety is a transitory emotional state of the human organism that varies in intensity and fluctuates over time. State anxiety is characterized by subjective, consciously perceived feelings of apprehension, tension, and heightened autonomic system activity (Spielberger, 1983). 
5. Noncontact (NC) was the control intervention of the experiment. Noncontact is defined as movement that mimicks al 1 the movements of NCTT except there is no intention to assist or heal the client, to center, to redirect energy or to fill in spaces with new healing energy. The nurse performing Noncontact made the intention to repeat the movements of Noncontact Therapeutic Touch (NCTT), but focused attention by mentally counting backwards from 500 by 5 's.

6. Preoperative is defined as 1 hour prior to surgery on the morning of surgery.

7. Chakras are nonphysical channels located at various areas on the body through which life energy is absorbed and released from the body (Boguslawski, 1979).

8. Electromyography is the study of electrical activity of muscle on a graphic record either spontaneously or in response to artificial electrical stimulation.

9. Coextensive fields are the fields of humans and their environment interacting equally or coincidentally in the time and space of the universe.

\section{Significance of the study}

Nursing has largely adhered to the mechanistic allopathic medical model for practice, education, and research (Wright, 1987). However, there is a growing theory base indicating a move toward holism (Wright, 1987) thus 
balancing science and technology with the human side of nursing care. There is a need to look at alternative healing practices in a society where rising health costs are, in part, the result of sophisticated technological advancements. Therapeutic Touch is one expression of a comforting nursing action which serves to alleviate the discomforts of illness. It can be used as a substitute for analgesics or sedatives for persons experiencing preoperative anxiety or postoperative pain. Other persons who cannot benefit from medical science application, such as terminal cancer patients, may benefit from Therapeutic Touch as a palliative treatment.

\section{Assumptions}

This study assumed that persons anticipating a personal threat or stressful event, such as surgery and hospitalization, would experience signs and symptoms of anxiety. These include a subjective awareness of their own anxiety, and objective measurable signs of a fight or flight response, as evidenced by eievated blood pressure, pulse, respiratory rate, tensing of the facial and neck muscles, and peripheral vascular vasoconstriction. Therapeutic Touch frequently elicits a condition of general relaxation, which includes flushing of the skin, lowering vocal pitch, and a subjective feeling of tranquility (Krieger, 1979). Therefore, clients under the stress of anticipated surgery 
should benefit from the positive effects of Therapeutic Touch and experience a reduction in their perceptions and physiologic sensations of stress.

The Experiment

The hypotheses in this study were: (a) there will be a greater decrease in posttest anxiety scores in preoperative clients treated with Therapeutic Touch without physical contact than in the control group treated with the Noncontact treatment; (b) the total mean decrease in blood pressure, pulse rate, respiratory rate, electromyographic activity and the total mean increase in peripheral skin temperature will be greater in preoperative clients who have been treated with Therapeutic Touch without physical contact, than in those treated with the Noncontact treatment.

Using a quasi-experimental design a voluntary sample of 12 clients were assigned to the treatment (NCTT) group, and 8 clients were assigned to the control (NC) group. They were selected from the surgical schedule at a 432 bed hospital in the san Francisco Bay Area. All ciients met the established criteria for selection and signed consents.

Approximately 1 hour before scheduled surgery time the client was escorted to a quiet room where pretreatment and posttreatment physiologic measurements were obtained. The instrument used to measure anxiety level of clients was the 
STAI-Y, State Anxiety Inventory Self-Evaluation

Questionnaire (Spielberger, 1983) [Appendix A]. The

researcher was the author and administered the NCTT

treatment. An assistant, who was unfamiliar with

Therapeutic Touch methods, administered the NC control

treatment. Finally, for clients in the treatment group, the NCTT practitioner completed a Therapeutic Touch Practitioner Self-Inventory.

The single sample $t$ test was used to analyze the mean, SD, $t$ value and $p$ value for (a) differences between pretest and posttest variables within each group, (b) variances in the pretreatment scores of both groups, and (c) differential values between group scores. Pearson Product-Moment Correlation Coefficients were calculated to test correlations of physiologic measurements with the researcher's perceived bonding with clients.

\section{Limitations}

One of the limitations of this study involved the voluntary and convenience method for sample selection of the clients. This type of sampling provided the largest number of clients in the shortest period of time. However, voluntary, convenience sampling was not as representative as a random sampling methodology, and findings cannot be generalized to other populations. 
Another limitation was the uncontrolled variable of degree of stress responses experienced by clients. It was anticipated that clients could experience a range of stress responses in anticipation of surgery. However, significant results were derived only when clients experienced anxiety at the beginning of treatment, then experienced a change after treatment. This was shown by examining mean pretest anxiety scores in both the experimental and control groups. One bias to the study was the author serving as both the researcher and the Therapeutic Touch practitioner. This dual role for the author was stressful. Some assessments were, questionably, more subjective than desired. A fourth limitation was using a short-stay surgical unit which experienced frequent, short-notice changes in scheduling. Because of this system, obtaining numbers of clients for the study was prolonged. 


\section{Chapter 2}

\section{REVIEW OF CONCEPTUAL FRAMEWORK}

\section{AND RELATED LITERATURE}

\section{Conceptual Framework}

Since the 17 th century, a mechanistic paradigm has been the established foundation for theoretical explanations of man and the universe. According to Cartesian philosophy, supported by Descartes, Bacon, Hobbes, and Hume, the universe is dualistic, with consciousness and matter in two distinct domains. This dualistic philosophy resulted in scientific beliefs and practices which divorced man and nature, mind and body, and logic and emotion. From a health sciences perspective supporting the mechanistic paradigm, health is defined as normalcy and disease as an abnormal condition to be controlled, manipulated and eliminated (Dossey, Keegar, Guzzetta, \& Kolkmeier, 1988). This paradigm suggests that the mind and body are separate entities.

Though the mechanistic view continues to dominate sciences such as biology and psychology, it has been challenged by a new holistic philosophy, and repudiated by modern theorists and scientists such as Bohm (1980), Capra (1982), Weber (1975, 1978), Battista (1977), and Rogers (1970, 1983). The holistic framework conceptualizes the 
universe as one open system, a hierarchy of dynamic wholes, tending to evolve toward an ever-increasing order and complexity (Keller, 1984). In this framework, the primary cause of disease is the disconnectedness from the flow and rhythm of the whole (Weber, 1981). Health is defined as high-level wellness, a positive sense of well-being, dynamic balance, and harmony (Keller, 1984).

The healing hypothesis (Weber, 1981) is a comporent of the holistic framework. The healing hypothesis is the basis of Therapeutic Touch practice, and includes the concepts of space, time, and energy. Energy and consciousness exist in various states with supremacy over gross physical matter. Healing power originates in the $\mathrm{N}$-dimensional space of pure spiritual energy, and increases in density and other physical properties as it enters the space-time sphere (Weber, 1981).

Nursing theorist, Martha Rogers (1970), supports the premise that Therapeutic Touch is part of a larger conceptual framework of energy exchange and energy fields. She proposes that healing occurs through mutual simultaneous interaction of man and environmental energy fields when one of the two fields works actively toward a direction of change. Rogers explains that all persons are highly complex fields of various forms of life energy which are coextensive with the universe and also in constant interaction with 
environmental fields. Via Therapeutic Touch, nursing seeks to enhance or strengthen human and environmental rhythmic field patterns toward the direction of positive health.

Further evidence about energy fields is supported by physicists. Guillemin (1968) states regarding the quantum field theory, "fields alone are real; they are the substance of the universe" (p. 175). Burr and Northrup (1935) state that, "the pattern and organization of any biological system is established by a complex electrodymanic field" (p. 329).

Hunt (1988) has conducted research in electromagnetic field theory. Using telemetry electromyography, she has been able to provide evidence of previously unrecorded frequencies from the body after massage and acupuncture. These frequencies were recorded only after extreme amplification of the baseline and were independent of tissue or muscle activity. Additionally, Hunt has:

1. Consistently matched psychically visualized colors with amplified electromyographic waveforms. Psychics were reading auras of people while they received psychic healings or while they were experiencing extreme stress and emotion.

2. Removed electromagnetic charge from the air and observed subjects become disoriented, emotional or would weep without emotion.

3. Identified coherency between readings of fields recorded over the heart area and solar plexus area. 
4. While using special photography equipment, recorded a video showing both human and environmental fields interacting with color alterations during meditation, during human and animal interaction, and during human and nature interaction.

5. Recorded amplified sounds of various colors present in the human field and used them in a variety of therapeutic situations.

6. Worked with ill persons to stabilize their energy fields. Hunt has had success in normalizing cardiac dysrhythmias, hiccoughs, and rapid, erratic respiratory patterns. She suggests that evidence supporting biochemical and physiological origins of illness and health will evolve toward a new model of elestromagnetic field theory.

An experiment described by Pavek (1987) using the techniques of Specific Human Energy Nexus (SHEN) Therapy provides evidence that the field effect is some medium other than body heat or weak electromagnetic field. SHEN is systematic, noninvasive energy bodywork used to normalize bio-emotional energy fields. SHEN is like Therapeutic Touch in that the practitioner uses energy in the hands to dissipate or replenish energy in the client. In Pavek's experiment, the practitioner placed his left, or receiving, hand in front of the solar plexus of the client and his right, or sending, hand behind the solar plexus. Three 
temperature gauges alternated by two foam pillow insulators were placed between the left hand and the front solar plexus area. One temperature gauge and pillow was placed between the right hand and back solar plexus area.

First, the temperature gauge in the sending hand rose several degrees then levelled to almost flat. second, about 1.5 seconds later, the client released a mild myoclonic jerk and breath rate slowed. Third, 10 seconds later, the temperature reading at the client's stomach began to rise, and 15 seconds after this event, the temperature at the receiving hand rose rapidly, nearly a degree, before levelling out. The temperature reading on the third probe between the two insulating cushions remained constant throughout the experiment. This experiment shows that there is a predictable sequence of energy-related events occurring between the hands of the practitioner. Pavek admits that this experiment was repeated several times with the same results. However, he does not specify the number of times the experiment was conducted, nor if the findings were consistent with one or multiple subjects.

Therapeutic Touch Research: Related Literature Related studies on Therapeutic Touch will be discussed in this section organized from the older broader studies to newer and more specific studies. During the 1960's, scientists conducted research experiments to investigate the 
power of supernatural healing. One self-proclaimed supernatural healer was oskar Estebany. Estebany claimed that his hands possessed a power that could cure individuals with certain illnesses (Heidt, 1981). The following three studies show the effects of Estebany's healing power on both plants and animals.

Grad (1961) conducted an experiment using barley seeds in a flask. In the experimental group, the flask was exposed to Estebany, who held his hand over the flask for 15 minutes. Grad found that the experimental group yielded a greater number of plants, which were taller, and had a greater yield for a period of 5 days.

Smith (1972) conducted studies which examined four solutions of the enzyme Trypsin. They were (a) a control solution, (b) a solution exposed to ultraviolet radiation and treated by Estebany, (c) a solution held by Estebany, and (d) a solution exposed to a magnetic field. Smith concluded that the activity of Trypsin was significantly stimulated by Estebany's treatment and the magnetic field as compared to the control group.

Grad, Cadoret, and Paul (1961) examined the rate of wound healing in mice. Half the mice were kept in a cage concealed in an open paper bag. The other half of the mice were kept in cages each sealed in a closed paper bag. For 15 minutes, twice daily, Estebany held the closed, bagged 
cages, then held directly, the metal cages that were openly bagged. After the 15 th and 16 th day there were significantly smaller wound size in mice whose cages were held directly by Estebany. The wound healing rates in mice whose cages were held by Estebany were significantly greater than the wound healing rates of mice in the nontreatment group, or in the group held by individuals who claimed no healing abilities.

The results of these plant and animal studies suggest an interchange of some energy force between the healer and the living organism. This energy interchange promotes healing or growth in the organism. similar experiments were conducted in attempts to determine if humans would also respond to intentional healing.

Dolores Krieger, a nurse-physiologist from New York, became interested in the ancient practice of laying-on of hands as an applied nursing practice during the 1970's. She asked Estebany to work with her on experiments to measure human hemoglobin levels. Hemoglobin was chosen as the dependent variable because it is a sensitive indicator of the body's oxygen uptake. Krieger (1976) reported a significant increase in the mean hemoglobin in Estebany's treatment group compared to a control group.

Krieger, who believes everyone has a natural healing ability which can be developed, refined the laying-on of 
hands process into Therapeutic Touch. After teaching nurses the technique, Krieger conducted experiments using nurses to administer either casual touch such as touching an arm, or Contact Therapeutic Touch on patients in a hospital setting (Rrieger, 1975). Since then, a variety of nursing studies have emerged researching the effects of Therapeutic Touch response on human subjects. These studies vary somewhat in the method of Therapeutic Touch and in the control treatments. Generally, most studies on the effects of Therapeutic Touch have shown favorable results. Whitcher and Fisher (1979) studied the effects of Therapeutic Touch during preoperative teaching on patients' affective, behavioral, and physiological responses. Their definition of Therapeutic Touch in the experimental group was having the nurse hold her hand on the subject's arm for one minute during teaching. The control group received no physical contact during teaching. Whitcher and Fisher found that females receiving the touch condition experienced more favorable reactions than the no touch group.

The remainder of the studies to be discussed in this chapter use Dolores Krieger's findings to establish background knowledge for their research. Randolph (1984) studied the response of 60 female college students' to stressful stimuli followed by Contact Therapeutic Touch (CTT). The study found no significant difference in charges 
of electromyographic skin conductance, or peripheral skin temperature response after CTT. Randolph suggested that the use of healthy subjects, and an absence of an assessment phase where the healer explores the subject's human field with her hands while attuning to sensory energy cues, may account for the lack of significant findings. Another study by Keller and Bzdek (1986) demonstrated the use of Noncontact Therapeutic Touch (NCTT) $\geqq s$ an effective healing modality in the relief of tension headache pain. In this study 908 of the experimental subjects and $80 \%$ of the placebo subjects experienced a reduction in headache pain after NCTT treatment. However, the experimental group's reduction in pain was $70 \%$, and sustained over a four hour period; while the placebo group had a $37 \%$ reduction in pain. Half of the placebo subjects reported an intervening headache during the four hour period following the posttest treatment.

Fedoruk (1984) examined the effects of Noncontact Therapeutic Touch (NCTT) as a method for reduction of stress in premature neonates. She found that infants treated with NCTT treatment demonstrated a greater change from a higher, more aroused state, to a more relaxed state over the course of observation. Findings were supported at the $\mathrm{p}=.0295$ level of significance. Mimic Therapeutic Touch (NC), used as the control treatment, increased infant state anxiety and 
arousal. Fedoruk believes this was related to using staff nurses who were anxious about doing a mimic Therapeutic Touch.

Meehan (1985) studied the comparative effects of mimic Therapeutic Touch (NC), Noncontact Therapeutic Touch (NCTT) and narcotic medication on pain reduction. subjects included 108 elective abdominal and pelvic surgical candidates on a postoperative hospital unit. A visual analogue scale was administered before and after the treatment. Results showed that while NCTT treatment caused a reduction in posttest pain scores, the decrease was not statistically significant. Additionally, NCTT treatment was found to be much less effective in decreasing pain compared to narcotic medication treatments. Meehan goes on to explain that she used the Tukey HSD tool to calculate her significance level. If she had used the Newman-Keuls tool to calculate significance, the means would have been 1.11 greater than the level required for significance.

Most closely paralleling the present study, is research conducted by Heidt (1980) and Quinn (1984). They describe the effects of Therapeutic Touch on state anxiety in hospitalized patients. Heidt (1980) studied 90 cardiovascular patients each of whom received one of three possible interventions, contact Therapeutic Touch (CTT), a casual touch (touching the arm), or no physical contact. 
Those patients who received no physical contact or casual touch did not experience reduced anxiety. Those patients who received the Contact Therapeutic Touch (CTT) intervention had significant reductions in posttest anxiety scores and state anxiety.

Most closely associated with this study, The Effects of Therapeutic Touch on State Anxiety and Physiological Measurements in Preoperative Clients, is research conducted by Quinn. Building on Heidt's work (1980), Quinn (1984) tested anxiety levels in cardiovascular patients. Quinn examined the effects of Noncontact Therapeutic Touch (NCTT) on state anxiety of hospitalized cardiovascular patients in order to lend support to the Rogerian premise of a human energy field. The subjects were 37 men and 23 women hospitalized in a cardiovascular unit of a medical center in New York City. The STAI-Y State Anxiety Inventory was administered both before and after treatment intervention. One treatment group received Noncontact Therapeutic Touch (NCTT) for 5 minutes, while the control group received the mimic Therapeutic Touch (NC) in which the therapist mimicked the touch intervention, but focused her attention by mentally counting and subtracting. Significant findings in Quinn's study support the hypothesis that there may be a greater decrease in postest anxiety scores in subjects 
treated with Therapeutic Touch (NCTT) than in the control (NC) subjects. Correlated $\underline{t}$ tests of group means supported the hypothesis.

\section{Summary}

Rogers proposed that healing occurs through interaction of human and environmental fields. Hunt measured electromagnetic fields in humans. Pavek used bodywork to normalize bio-emotional energy fields. The findings of this study of preoperative clients are intended to lend support to the broader conceptual system proposed by Rogers (1970, 1983), and suppported by Hunt (1988) and Pavek (1987); that healing involves a transfer of energy between fields. While this study paralleled that of Quinn (1984) in hypotheses, treatment and control intervention, instrument, and calculation of findings, a different population was studied and additional physiological measures indicative of stress response were obtained. 
Chapter 3

\section{RESEARCH DESIGN AND METHODOLOGY}

Approval for the study

The proposal was approved prior to data collection by the Human Subjects Review Board of San Jose State University (see Appendix B) and the Nursing Research Comnittee and Institutional Review Committee (see Appendix C) of the hospital. Physician consent for client participation was obtained prior to commencement of data collection. Eight physician-surgeons gave verbal and written consent (see Appendix D) permitting any of their patients to participate in the study, provided the patient also gave consent.

\section{Sample and setting}

The researcher obtained names of potential candidates from a surgery roster 1 to 2 weeks prior to the client's surgical admission. Names were chosen from clients of the consenting physicians. The best method of obtaining client consent was by a phone call, no more than 1 week prior to the scheduled surgery. When mailed consents were attempted, most clients either did not respond, or did not receive the information. The shorter the time between the phone call and the scheduled surgery date, the greater the opportunity of obtaining the client for the study. All selected clients 
met the criteria for participation in the study (see Appendix E), Voluntary participation was reinforced verbally.

To comply with the criteria for participation clients had to:

1. be over age 18 .

2. be able to read and complete the English version of the Self-Evaluation Questionnaire (Spielberger, 1983).

3. be able to participate for the length of time needed in the research.

4. agree to participate in the study on the day of and prior to their scheduled surgery.

5. have surgery under general anesthesia.

6. have surgery which involved removal or repair of body tissue. Previous hiztory of surgeries was acceptable. Surgeries for immediate life-threatening situations (trauma, shock, system failure) were not acceptable. Diagnostic tests were not acceptable.

7. not have had Therapeutic Touch performed on them previously nor have practiced meditation or relaxation techniques more than three times within the past year.

8. have their physician's consent obtained.

9. not be acquainted with the researcher or assistants. 
The clients were informed of the risks and benefits of participation. One possible benefit may have been relaxation. A risk rarely encountered in previous studies was dizziness or lightheadedness after the Therapeutic Touch treatment. Clients were given the option to withdraw at any time. They were told that their decision to participate or not participate in the experiment would in no way prejudice their relations with the hospital or San Jose state University.

Using a quasi-experimental design, 12 clients were assigned to the Noncontact Therapeutic Touch (NCTT) treatment group and 8 clients received the Noncontact (NC) control treatment. The decision about selection in the control group or experimental group was based on convenience. If the control assistant was available on a particular day, then all clients on that day were given the Noncontact (NC) treatment. The criteria selection for age was changed to include anyone over the age of 18 years. Using an age range of between 21-65 years excluded too many potential clients. The anticipated time frame for data collection was 6 weeks, but, in fact, became a 10 month project. Although there were approximately 150-200 potential clients' names submitted by the surgery department scheduling coordinator, only a total of 20 clients participated in the study. 
The following factors contributed to the smaller sampling size and extended the length of the study.

1. Clients could not be contacted by phone even though two or three attempts were made. Some phone numbers were not listed on the surgical roster, or were incorrect.

2. Approximately 108 of clients refused to consent due to severity of illness, feeling overwhelmed, lack of interest, or religious reasons.

3. Some clients were inpatient admissions prior to their surgeries, and thus were ineligible for the study.

4. The surgery department would frequently change or cancel the time of surgery, sometimes within minutes or hours of the surgery.

5. Many clients' preoperative preparation took longer than the average time and therefore, not enough time was available for them to participate. Relating to this was the practice of a few anesthesiologists in visiting clients during the period that the client would be participating in the study.

6. The biofeedback room was not available due to other patient appointments.

Timeliness was essential to this study. The study had to be conducted exactly 1 hour before surgery in order to be in accordance with the schedule of the surgical procedure. This close time interval was beneficial in providing 
internal consistency of data collection operation. However, the acquisition of numbers of clients was tedious.

There were a total of 20 participants. In the experimental group there were 12 participants. The mean age was 58 years. There were 5 men and 7 women. In the control group there were 8 participants. The mean age was 41 years. There were 4 men and 4 women. Table 1 provides information on the eight types of surgeries; 508 of them were nose or throat surgeries.

Table 1

Types of Participant Surgical Procedures $\quad \mathbf{N}=20$

Type of Surgery Experimental Group Control Group
$\underline{\mathrm{n}}=12$
$\underline{\underline{n}}=8$

Nose/Throat

Inguinal Hernia

Genitourinary

Mastectomy

iñterior Cruciate

Ligament Repair

Lobectomy

Leg Lymphoma

Anal Fistula

64

21

2

1

1

1

1

1 
The biofeedback room at the hospital was selected as the setting because of its quiet, isolated location; comfortable chair; and biofeedback equipment. After registering through the outpatient department, clients went to the Surgical short stay Unit to prepare for surgery. Once they were in that unit they were greeted by the researcher and escorted to the biofeedback room.

Due to the long duration of the study, only the researcher and a control assistant participated in the data collection phase. The author and researcher, who administered the NCTT treatment, had 3 years of experience using Therapeutic Touch technique. The control assistant was a female pharmacist employed at the hospital. She had no knowledge of the technique of Therapeutic Touch. She was trained to mimic the hand movements of Therapeutic Touch while mentally counting backwards by 5's from 500. Her ability to perform this technique was demonstrated in practice sessions using volunteers. Also, to help insure internal validity, the client's diagnosis and type of surgery to be performed was withheld from her.

Methods of Data Collection

Once in the biofeedback room, clients signed consent forms. A copy of both the consent and the Experimental Subject's Bill of Rights (see Appendix F) was given to clients. The process of data collection began with 
measurements of the client's state anxiety using the STAI-Y, State Anxiety Inventory, Self-Evaluation Questionnaire. The essential qualities evaluated in this state anxiety scale are feelings of apprehension, tension, nervousness and worry (Spielberger, 1983, p. 2). The reliability of STAI-Y state Anxiety Inventory, Self-Evaluation Questionnaire as a testing instrument was demonstrated in studies which included 1,835 employees of the Federal Aviation Administration, 77 college students in introductory psychology courses at the University of Florida, and 1,964 military recruits (Spielberger, 1983, p. 5). Spielberger (1983) notes that because anxiety states are cransitory, the alpha coefficient measure provides a more meaningful index of reliability of S-Anxiety than for test-retest correlations (p. 13). The median alpha coefficient for S-Anxiety was .93, indicating a high degree of consistency.

other tests measuring convergent and divergent validity correlations between the STAI scales and the Cornell Medical Index show that the Cornell Medical Index correlated at a measurement of .70 with the S-Anxiety scale. Thus indicating that a large number of medical symptoms are associated with high STAI scores (Spielberger, 1983, p. 16).

In this study of The Effects of Therapeutic Touch on State Anxiety and Physiological Measurements in Preoperative clients, the 20-item questionnaire was easy to administer. 
The scoring for state anxiety on the form ranged from a minimum of 20 to a maximum of 40 . The lowest score represented the absence of anxiety. The highest score represented high state anxiety. After the STAI-Y State Anxiety Inventory was administered, blood pressure was measured on the left arm using the Paramed Cardivan 9200. In order to obtain an accurate measurement of the client's blood pressure, the average of two consecutive readings were measured. Current recommendations from the National Institutes of Health (1988), were used to insure tester reliability. $J$ \& J Biofeedback software was used to measure heart rate and peripheral skin temperature. To obtain heart rate measurements, a photophlethysmograph was placed on the thumb of the left hand. One reading was taken every 10 seconds for 1 minute, then averaged.

To record measurements of peripheral skin temperature, a thermistor was taped to the fifth finger of the right hand, a reading was taken every 10 seconds over 1 minute, then averaged. This location was selected because the vascular nervous system responds by vasoconstriction of the blood vessels in the extremities, thereby decreasing skin temperature of the arms and legs (Fuller, 1977). The client's respirations were counted for I minute based on the rising of the chest wall. About 508 of the treatment group measurements were taken by the assistant. All other 
measurements were taken by the researcher. Additionally. the same instruments were used on each client.

Electromyography was eliminated as a testing procedure. In a practice testing session, the length of time needed to attach electromyographic leads and record results was about 10 minutes. This additional time would have interfered with the client's surgery schedule. There were two individuals whose heart rate and skin temperature readings could not be measured by the instruments because both had cold hands and poorly palpable radial pulses. One person admitted to having Raynaud's Disease which causes vasoconstizicion of the peripheral vasculature. Data on heart rate and skin temperature for these two individuals was omitted from the study.

Next, the Therapeutic Touch was performed by the researcher, or the control treatment was performed by the assistant for a period of 5 minutes. The researcher used the techniques of intention, centering, attuning, and redirecting energy around the field, as she moved her hands around the client's field. The control assistant mimicked the appearance of technique, but was mentally counting bachiards from 500 by 5 's. Immediately following the treatment the researcher repeated the measurements of blood pressure, heart rate, respiratory rate, and peripheral skin temperature. The STAI-Y state Anxiety Inventory was again 
completed by the clients. Posttreatment physiological

measurements were taken in the same manner as pretreatment

measurements. The total data collection time on each client was 30 minutes. The client was then escorted back to the Short stay Unit. On all clients who received the Therapeutic Touch treatment, the researcher filled out the Therapeutic Touch Practitioner Self-Inventory (see Appendix G). 
Chapter 4

RESULTS AND DATA ANALYSIS

This chapter describes the data collected, and the parametric levels of measurement used to analyze the data. The purpose of this study was to answer two questions:

1. What is the effect of Therapeutic Touch administered without physical contact on state anxiety of preoperative clients?

2. What is the effect of Therapeutic Touch administered without physical contact on blood pressure, pulse rate, respirations, peripheral skin temperature, and electromyographic activity of preoperative clients?

\section{Results}

Using a quasi-experimental design, 12 clients were assigned to the Noncontact Therapeutic Touch (NCTT) treatment group, and 8 clients received the Noncontact (NC) control treatment. The selection of clients to a particular group was a convenience sampling, based on availability of the control assistant. The participant age range was 21-65 years including 9 males and 11 females. There were eight categories of surgeries and $50 \%$ were nose and throat surgeries. The anticipated time frame for data collection was 6 weeks, but lasted for 10 months. Although there were 
150-200 potential clients' names submitted by the surgery department scheduling coordinator, only a total of 20 clients participated in the study.

Each client received pretest and posttest measurements of blood pressure, respiratory rate, heart rate, peripheral skin temperature and completed the STAI-Y state Anxiety Inventory self-Evaluation Questionnaire. The control or treatment intervention between the physiological measurements was administered for 5 minute period.

\section{Within-Group Measurements}

Using the single sample $t$ test, both the control and experimental groups had measurements which reflect significant relaxation responses. Tables 2 and 3 show the mean, standard deviations, $t$ value, and level of significance for differences between pretest and posttest variables studied within each group.

The control group showed statistically significant ( $p^{<.05)}$ increase in skin temperature, decrease in respiratory rate, and decrease in state anxiety scores from pretest to posttest measurements. The experimental group showed statisticaliy significant $(\mathrm{R}<.05)$ increase in skin temperature, decrease ir: state anxiety scores, and decrease in systolic blood pressure from pretest to posttest measurements. However, in this group, there was significant 
increase in respiratory rates at the $R=.04$ level, which did not correspond to the physiologic relaxation response and cannot be explained.

Table 2

Differences between Pretreatment and Posttreatment Measurements within the Control Group $(N=8)$

\begin{tabular}{lrrrc}
\hline Variable & Mean & SD & $t$ & D \\
\hline Systolic BP & -2.75 & 6.98 & -1.11 & .30 \\
Diastolic BP & -1.63 & 5.18 & -.89 & .40 \\
Temperature & .63 & .72 & 2.44 & $.04 *$ \\
Respiratory Rate & -.88 & .83 & -2.97 & $.02 *$ \\
Heart Rate & 1.50 & 2.33 & 1.82 & .11 \\
STAI Scores & -5.75 & 5.18 & -3.14 & $.02 *$ \\
\hline
\end{tabular}

Note: $B P=$ blood pressure

$a \underline{p}=8$ for all variables

$* \mathfrak{p}<.05$ 
Table 3

Diffefences between Pretreatment and Posttreatment

Measurements within the Experimental Group $(N=12)$

\begin{tabular}{lrrrrr}
\hline Variable & $\underline{\mathrm{n}}$ & Mean & $\underline{\text { SD }}$ & $\underline{t}$ & $\mathrm{R}$ \\
\hline Systolic BP & 12 & -5.08 & 6.82 & -2.58 & $.03 *$ \\
Diastolic BP & 12 & -.83 & 7.16 & -.40 & .69 \\
Temperature & 10 & 2.46 & 3.27 & 2.38 & $.04 *$ \\
Respiratory Rate & 12 & 1.17 & 1.75 & 2.31 & $.04 *$ \\
Heart Rate & 10 & -1.00 & 3.40 & -.93 & .38 \\
STAI Scores & 12 & -4.33 & 5.35 & -2.81 & $.02 *$ \\
\hline
\end{tabular}

Note: $\mathrm{BP}=$ blood pressure

${ }^{*} \mathrm{p}<.05$

Pretreatment Variables

Equal variance tests were used to analyze all

pretreatment measurements. There were no significant

differences in systolic or diastolic blood pressure readings, temperature, respiratory rates, or STAI-Y State Anxiety scores between the Pretreatment groups. There was, however, a significant difference $(\underline{p}<.01)$ in the heart rate between the control and experimental group. The control group's baseline pretreatment values were lower than the experimental group scores. Therefore, further reductions in 
control group heart rate after treatment were not expected to occur. Table 4 specifically, shows that the variance in heart rate was at the $\mathrm{p}<.01$ level of significance.

Table 4

Control and Experimental Group Pretreatment Heart Rate Measurements $N=20$

$\underline{n}$ Mean $\underline{\underline{S D}} \underline{t} \quad \underline{\mathrm{t}} \quad \mathrm{p}$

$\begin{array}{lrrr}\text { Control } & 8 & 67.50 & 8.10 \\ \text { Experimental } & 12 & 77.90 & 5.95\end{array}$

Variances $-3.14 \quad 16.0 \quad .006 *$

${ }^{\star} \mathrm{p}<.01$

Differential Variables

Equal variance tests were used in analysis of all measurements except one, a client whose slin temperature increased by 10 degrees from pretest to posttest measurements. On this client an unequal variance test was used in the analysis of peripheral skin temperature. There was no significant increase in relaration between the experimental and the control group. All systolic and diastolic blood pressure, skin temperature, heart rate measurements, and STAI-Y state Anxiety scores from pretest 
to posttest period show no statistically significant changes when comparing the values between groups.

An unpredicted outcome was the significant ( $p<.01)$

increase in respiratory rate of the experimental group while the control group showed a decrease in values (see Table 5). This phenomena may have occurred because of rater unreliability. The clients' respirations were counted for 1 minute based on the rising of the chest wall. About 508 of the treatment group measurements were taken by the assistant. All other measurements were taken by the researcher. The control assistant admitted to having difficulty, at times, visually observing the chest rise through clothing. Also, if a client knows he or she is being observed for respiratory rate, this self-consciousness often wills the client to control his or her rate, and breathing no longer is an autonomic response. Nurses are trained to count respirations while they are palpating a radial pulse or auscultating the chest. In this manner, the client may not notice that respirations are being counted. In this study, respirations were counted usually when the researcher was sitting across from the patient, and had to observe the respiratory rate for a full minute. The client was more likely to be aware of this attention and of his or her own respiratory rate. 
Table 5

Control and Experimental Group Respiratory Rate Differential Values $N=20$
n Mean
SD $t$ DE
P

$\begin{array}{lrrr}\text { Control } & 8 & -.88 & .83 \\ \text { Experimental } & 12 & 1.17 & 1.75\end{array}$

Variances

$-3.0618 .0 \quad .007 \star$

$\star_{p}<.01$

The heart rate pretreatment value varied significantly between groups. Although there was no statistical significance in the difference of heart rate changes between groups, the pretreatment value may have undermined the significance of the differences. More subjects were needed in order to justify the confounding of analysis of the differences in pretreatment values.

Therapeutic Touch Practitioner self-Inventory Results

The last questions posed to the client by the researcher after data collection were an attempt to quantify the subjective measurement of bonding that may have occurred between the experimenter and client when Therapeutic Touch was administered. On a scale of 1 to 5 the researcher reported the level in which she felt centered, bonded with 
the client, and a sensation of energy change during the treatment (see Appendix G). Pearson Product-Moment Correlation Coefficients were calculated on each variable. $\overline{\text { A }}$ positive correlation $\left(\mathrm{R}^{<.01}\right)$ was found between increase in peripheral skin temperature and increase in the researcher's feelings of centeredness, bonding with the client, and energy sensation (see Table 6 ). Other measurements of blood pressure, respiratory rate, heart rate, and STAI-Y state Anxiety scores were not statistically significant.

Table 6

Pearson Product-Moment Coefficients Correlation of Perceived Bonding of Practitioner to client in Relationship to Measured Differential Variables During Therapeutic Touch

Variable $\underline{n}$ Pearson $\underline{r} \quad \underline{p}$ value

\begin{tabular}{lccc}
\hline Systolic BP & 12 & -.11 & .74 \\
Diastolic BP & 12 & .35 & .26 \\
Temperature & 10 & .80 & $.006 *$ \\
Respiratory Rate & 12 & .29 & .35 \\
Heart Rate & 10 & .02 & .95 \\
STAI Score & 12 & -.08 & .81 \\
\hline
\end{tabular}

Note: $B P=$ blood pressure

* $\mathrm{p}<.01$ 
The Hypotheses and Results

I test procedures on both physiologic measurements and anxiety scores were used to test the following hypotheses: (a) There will be a greater decrease in posttest anxiety scores in preoperative clients treated with Therapeutic Touch without physical contact, than in the control group treated with the Noncontact treatment, and (b) the total mean decrease in blood pressure, pulse rate and respiratory rate, and the total mean increase in peripheral skin temperature will be greater in preoperative clients who have been treated with Therapeutic Touch without physical contact, than in the control group treated with the Noncontact treatment. Neither of these hypotheses we:e supported at a statistically significant level. 
Chapter 5

CONCLUSIONS AND RECOMMENDATIONS

Conclusions

This study posed two questions:

1. What is the effect of Therapeutic Touch

administered without physical contact on state anxiety of preoperative clients?

2. What is the effect of Therapeutic Touch administered without physical contact on blood pressure, pulse rate, respirations, peripheral skin temperature and electromyographic activity of preoperative clients?

Using a guasi-experimental, pretest, posttest design, 12 clients received the Noncontact Therapeutic Touch (NCTT) intervention, and 8 clients received the Noncontact (NC) control treatment. The sampling included 9 males and 11 females between the ages of 21-65 years, who were seen 1 hour prior to having a surgical procedure performed in an acute care hospital facility. The STAI-Y state Anxiety Inventory Self-Evaluation Questionnaire was used to measure state anxiety.

This study had a replication design based on previous studies by Heidt (1980) and Quinn (1984). Heidt and Quinn found that there was a greater decrease in STAI-Y State Anxiety scores from pretest to posttest in groups 
administered the Therapeutic Touch treatment (NCTT), than in the control (NC) groups administered a mimic treatment. The findings of this study did not support those of either Heidt (1980) or Quinn (1984). While there were significant relaxation increases in both groups, the experimental group did not have a greater mean decrease in posttest anxiety scores, blood pressure, heart rate, or respiratory rate, or increase in peripheral skin temperature than the control group. Additionally, there was an unexplainable response by the experimental group in demonstrating significant increase mean respiratory rates, which were inconsistent with other measurements indicative of relaxation by that group. The findings cannot be generalized because of the small size of the sample, and the resulting small number of subjects in both the quasi-experimental and control groups.

One of the most remarkable findings of this study was the marked increase in relaxation responses by both posttreatment groups exhibited as significant increase in skin temperature, and decrease in state anriety. The experimental group also experienced a decrease in systolic blood pressure. Using human subjects for experimental design could create uncontrolled variables in both ethical and psychological considerations. One such influence seen in this study may have been the Hawthorne effect. When clients agreed to participate, they were told it was a study 
of the effects of Therapeutic Touch on relaxation. This attention given to the focus on relaxation may have resulted in the positive response. Furthermore, all of the conditions of the experiment were designed to promote relaxation. They included a small quiet room, a comfortable chair, minimal conversation, and a 30 minute time frame. The client was in an optimal environment to focus his or her attention on the stress of impending surgery, and releasing the tension experienced in the busy hospital surgical preparation area.

On the other hand, the question is raised as to whether energy (Govinda, 1974) or prana (Weber, 1981) was transferred through the hands of the control assistant as well as the experimenter. Quinn (1989) suggests from her experiences, that intention to block helpfulness or energy transfer cannot consciously be controlled. Studies by Heidt (1980) and Quinn (1984) have demonstrated that the ability to transmit healing energy is not unique, but rather universal to all individuals. The control groups in separate studies by Heidt (1980) and Quing (1984), experienced a total mean decrease of 4.58 in state anxiety. Brennan (1987) suggests that persons who practice Therapeutic Touch and healing skill strengthening techniques improve with practice. Other individuals such as oskar Estebany (Heidt, 1981) have greater power in Therapeutic 
Touch ability than the average person. In this study, the control assistant was not screened for her healing abilities, therefore her degree of natural healing ability was unknown.

A high, but questionably biased, positive correlation was identified between increase skin temperature and a sense of bonding or connection with clients by the researcher who administered Therapeutic Touch. The bias may be or was related to the researcher's knowledge of the clients' physiologic measurements prior to the completion of the Therapeutic Touch Practitioner Self-Inventory. The researcher sensed, according to her responses, that she had a more perceivable energy exchange with clients who had the highest skin temperature increase.

This issue raiges the question of how nurses and other health professionals facilitate the healing process in clients. Krieger (1976), Weber (1981), Rogers (1983), and Quinn (1984) refer to the concept of energy exchange between nurse and client and between the client and environment. They studied the effects of the exchange but have not been able to define this energy. In their interactions with clients, clinicians often establish a unique rapport or connection expressed as a mutual exchange of communication, receptivity, positivity, and healing. In a positive therapeutic relationship, clients often progress steadily 
toward a state of wellness. What is this energy? Is it related to the positive effects of Therapeutic Touch? In the bonding with clients, there may be a physical energy exchange. The Therapeutic Touch practitioner experienced sensations of light pressure, increased warmth and perceived change in the clients' fields. Clients, also, experienced the physiologic changes of increased vasodilation of the peripheral vasculature which resulted in increased skin temperature. Three persons had spontaneous comments after treatment; the first felt relaxed and sleepy, the second noted relaxation of the hands, and the third had sinus drainage from the nose.

\section{Recommendations}

The following are recommendations for future study.

1. Replicate this study using a larger sample of at least 30 persons in each treatment group. This permits randomization to counterbalance values which may be atypical.

2. Replicate this study, and withhold from clients the implication that the study will test responses to a relaxation treatment. clients should be told only that physiologic measurements and a self-evaluation questionnaire would be taken. This may eliminate the possibility of Hawthorne Effect. 
3. Using a surgical patient sampling just prior to anticipated surgery provided both a consistent sampling selection and timely data collection interval. However, the hospital surgery unit used in the study was complex, with unpredictable procedural and systematic requirements. Thus, the acquisition of clients for this quasi-experimental design was a long-term tedious process. In replicating the study, other, more convenient parient populations within the hospital, should be accessed. Examples of potential client populations include: sleep study candidates suffering from sleep deprivation, oncology or cardiovascular patients, postoperative inpatient populations, or patients with life-threatening dysrhythmias. Use of inpatients would facilitate sample selection in other studies.

4. Replicate the study using no treatment as a control. This would answer the question of whether any hand movement around a cliert's field affects relagation. Also a comparison between the effects of a relaxing environment versus a relasing environment with a Therapeutic Touch intervention could be tested.

5. As Quinn (1989) suggests, large scale replication research is needed to test Therapeutic Touch. Furthermore, other studies need to evaluate outcomes of Therapeutic Touch, as well as exploring theory development. These future studies should examine the effects on clinical 
outcomes such as amount of anesthesia required during surgery, wound healing rates, recovery time, and amount of pain medication required for pain reduction. Therapeutic Touch is a valuable, noninvasive, palliative measure which promotes patient comfort. Those practicing nursing care could consider Therapeutic Touch a worthwhile tool. Nevertheless, there is little known about the technique that is explainable wichin a scientific scope.

Implications for Nursing Practice

Martha Rogers (1970) proposed that all persons are highly complex fields, coextensive with the universe, and that nursing seeks to enhance or strengthen human and environmental rhythmic field patterns toward the direction of improved health. Traditionally, nursing has adhered to the mechanistic, allopathic model. A move toward holism in nursing practice would balance science and technology with the human side of care. Therapeutic Touch is a holistic healing modality which may strengthen the human rhythmic field pattern. It is used by nurses as a complimentary, health-oriented, inexpensive intervention which potentiates the natural or self-healing process.

According to the literature reviewed in this study, Therapeutic Touch has improved physical comfort levels in patients. It has promoted relaxation, reduced pain, cramps or nausea, lowered blood pressure, reduced edema, and 
resolved fevers. Terminal cancer patients, who cannot benefit from medical science applications, may be aided by the palliative effects of Therapeutic Touch. However, the value of Therapeutic Touch goes beyond physical comfort. Based on this author's experiences, once the patient is relaxed by Therapeutic Touch, a channel for communication opens between the nurse and patient. Patients may express anxieties and fears about the outcomes of their illness. Thus, healing of emotion can occur. Other spiritual distresses may emerge. Patients may be able to discuss their unhealthy lifestyles, examine the meaning of their relationships, and explore the value of forgiveness and letting go. Ultimately, the patient may look at how the illness has or will affect his or her own quality of life. The findings of this study suggest that significant relaxation occurred with preoperative clients in a relatively short period of time ( 30 minutes). The relaxation occurred even though the candidates were experiencing a moderate level of anxiety, which was relatively normal in response to a stressful event. The value of relaxation in preparing the patient psychologically and physiologically for the stressful event of surgery needs to be indicated through further studies. For many patients, hospitalization is a time when there is greatest need for personalization and comfort. Hospitalization is a time when 
the intricate physio-psycho-spiritual balance of the patient's well-being is most at risk. Patients need to be comforted during their experience of overpowering emotions such as fear of death, the unknown, or intense effects of pain, surgery, anesthesia, and drugs. Ethically, hospitals should not become institutions for phisical repair and maintenance. In holism, all components of the person and environment are intricately interrelated. Therefore, health care providers are responsible for preparing and assisting patients in their total personal challenge toward homeostasis and positive health.

How can nurses in a hospital setting facilitate the holistic healing process in patients? One suggestion is for nurses to be trained in a variety of relaxation techniques including Therapeutic Touch; some could work exclusively with patients to promote relaxation and comfort through holistic practice. The relaxation and opening techniques of Therapeutic Touch help construct a strongly positive mental framework for the patient to experience a sense of well-being. This plan needs to be recognized and supported by nursing administrative and self-governance leaderships within hospital settings, and incorporated into long-term fiscal planning structures.

The art of nursing is expressed with focus on patient comfort, nurturing, and support. Nurses should continue to 
hold mastery of the tools of the art. These include the human presence, Therapeutic Touch and the skills of communication. Although in its infancy of understanding, the practice of Therapeutic Touch has been demonstrated as a valued and complementary holistic healing modality to the nursing profession. 
REFERENCES 


\section{References}

Battista, J. (1977). The holistic paradigm and general systems theory. General Systems Journal, 22, 65-71. Boguslawski, M. (1979). The use of therapeutic touch in nursing. The Journal of Continuing Education in Nursing, $10(4), 9-15$.

Boguslawski, M. (1980). Therapeutic touch: A Eacilitator of pain relief. Topics in Clinica! Nursing, 2(1), 27-37. Bohm, D. (is80). Wholeness and the implicate order. London: Routledge, Keegan \& Paul. Borelli, M., \& Heidt, P. (1981). Therapeutic touch: A book of readings. New York: springer.

Brennan, B. (1987). Hands of light. Toronto: Bantam Books. Burr, H.S., \& Northrup, F.S. (1935, September). The electrodynamic theory of life. Quarterly Review of Biology, pp. 322-333.

Capra, F. (1982). The turning point. New York: Simon \& schuster.

Dossey, G., Keegan, L., Guzzetta, C., \& Kolkmeier, L. (1988). Holistic nursing: A handbook for practice (p. 68). Rockville, Maryland: Aspen.

Fedoruk, R.B. (1984). Transfer of the relaxation response: Therapeutic touch as a method of reduction of stress in premature neonates. Unpublished doctoral dissertation, University of Maryland. 
Fuller, G. (1977). Methods and procedures in clinical practice. San Francisco: Biofeedback Institute of San Erancisco.

Govinda, L. (1974). Eoundations of Tibetan mysticism. New York: Samuel Weiser.

Grad, B. (1961). Influence of unorthodox methods of treatment on wound healing in mice. International Journal of Parapsychology, 3, 5-24.

Grad, B., Cadoret, R., \& Paul, G. (1961). An unorthodox method of treatment of wound healing in mice. International Journal of Parapsychology, 3, 5-24.

Guillemin, V. (1968). The story of quantum mechanics. New York: Charles Scriber's Sons.

Heidt, P. (1980). Effect of therapeutic touch on anxiety levels of hospitalized patients. Nursing Research, 30(1), $32-37$.

Heidt, P. (1981). Scientific research and therapeutic touch. In D. Borelli \& P. Heidt (Eds). Therapeutic touch (pp. 3-12). New York: Springer.

Hunt, V. (1988, May). Scientific validation of human electromagnetic fields. In G. Araki (Chair), The tao of healing. Symposium conducted through the Institute of Holistic Healing studies at San Francisco state University, San Francisco. 
Juzgens A., Meehan, T.C., \& Wilson, H.L. (1988, Spring). Therapeutic touch as a nursing intervention. Cooperative Conrection: Newsietter of the Nurse Healers, pp. 1, 4, 6-8.

Keller, E.A.K. (1984). Therapeutic touch: A review of the literature and implications of a holistic nursing modality. Journal of Holistic Nursing, 2(1), 24-28. Keller, E., \& Bzdek, V.M. (1986). Effects of therapeutic touch on tension headache. Nursing Research, 35(2), 101-106.

Krieger, D. (1s75). Therapeutic touch: The imprimatur of nursing. American Journal of Nursing, 75, 784, 787. Krieger, D. (1976). Healing by the "laying on" of hands as a facilitator of bioenergetic change: The response of vivo hemoglobin. Psychoenergetic systems, 1, 121-129. Krieger, D. (1979). The therapeutic touch. How to use your hands to help or heal. Englewood Cliffs: Prentice-Hall. Meehan, T.C. (1985). The effect of therapeutic touch on the experience of acute pain in postoperative patients. Unpublished doctoral dissertation, New York University, New York.

National Institutes of Health. (1988). Report of the joint national committee on detection, evaluation and treatment of high blood pressure. (NIH Publication No. 88-1088) Washington D.C.: U.S. Government Printing office. 
Pavek, R.R. (1987). The health erofessional's handbook of SHEN physioemotional release therapy. Sausalito, CA: The SHEN Therapy Institute.

Quinn, J.F. (1984). Therapeutic touch as energy exchange: Testing the theory. Advances in Nursing science, $6(2)$, $42-49$.

Quinn, J.F. (1989). Future directions for therapeutic touch research. Journal of Holistic Nursing, I(1), 19-25. Randolph, G.L. (1984). Therapeutic and physical touch: Physiological response to stressful stimuli. Nursing Research, 33(1), 33-36.

Rogers, M.E. (1970). An introduction to the theoretical basis of nursing. Philadelphia, PA: F.A. Davis. Rogers, M.E. (1983). Unitary human beings: A paradigm for nursing. Beginnings, 2 (6) 1-3.

Smith, J. (1972, January). Paranormal effects on enzyme activity. Human Dimensions, pp. 15-19.

Spielberger, C.D. (1983). Manual for the state trait anxiety inventory. Palo Alto, CA: Consulting Psychologists.

Weber, R. (1975). The good, the true, the beautiful: Are they attitudes of the universe? Main Currents in Modern Thought, 32, 118-125. 
Weber, R. (1978). The enfolding-unfolding universe: A conversation with David Bohm. Revision: A Journal of Knowledge and Consciousness. 1, 24-51.

Weber, R. (1981). Philosophical foundations and frameworks for healing. In M. Borelli \& P. Heidt (Eds.) Therapeutic touch (pp. 13-39). New York: Springer. Whitcher, S.J., \& Fisher, J.D. (1979). Multidimensional reaction to therapeutic touch in a hospital setting. Journal of Personality and Social Psychology, 37(1), 87-96. Wright, S.M. (1987). The use of therapeutic touch in the management of pain. Nursing clinics of North America, $\underline{22}(3), 705-714$. 
APPENDIXES 
APPENDIX A

Client Questionnaire 
PLEASE NOTE

Page(s) not included with original material and unavailable from author or university.

Filmed as received.

63, Appendix A

University Microfilms International 


\section{APPENDIX B}

Approval by Human Subjects Institutional Review Board:

San Jose State University 


\title{
SAN JOSE STATE UNIVERSITY \\ GRADUATE STUDIES AND RESEAKCH
}

\section{HUMAN SUBJECTS INSTITUTIONAL REVIEW BOARD PROJECT PROPOSAL REVIEW}

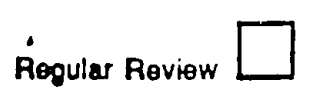

\author{
Expodiled Roviow $\sqrt{ }$
}

Deadline Date

I, the undersigned member of the San Jose State University Human Subjects Institutional Review Board, have reviewed the lollowing proposal submitted to the Board on $4 / 17 / 89$ by:

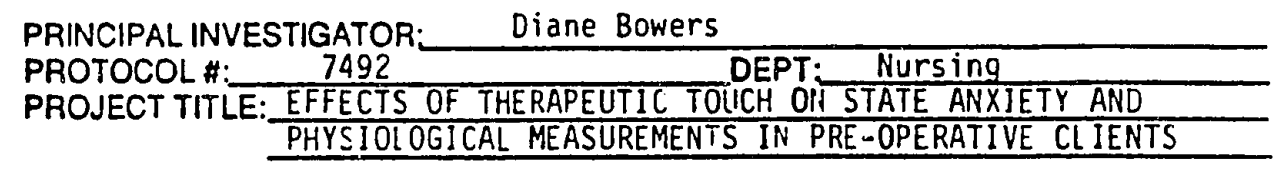

I recommend the following action (indicate one):

1. Approved for clearance as involving minimal risk to Human Subjects.

2

2. Approved for clearance with risk to Human Subjects.

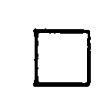

3. Approval depends upon the satisfactory completion of the lollowing conditions. The Quive be üset $l$

4. I have serious concerns about this protocol and it should go before the full commitlee to review.

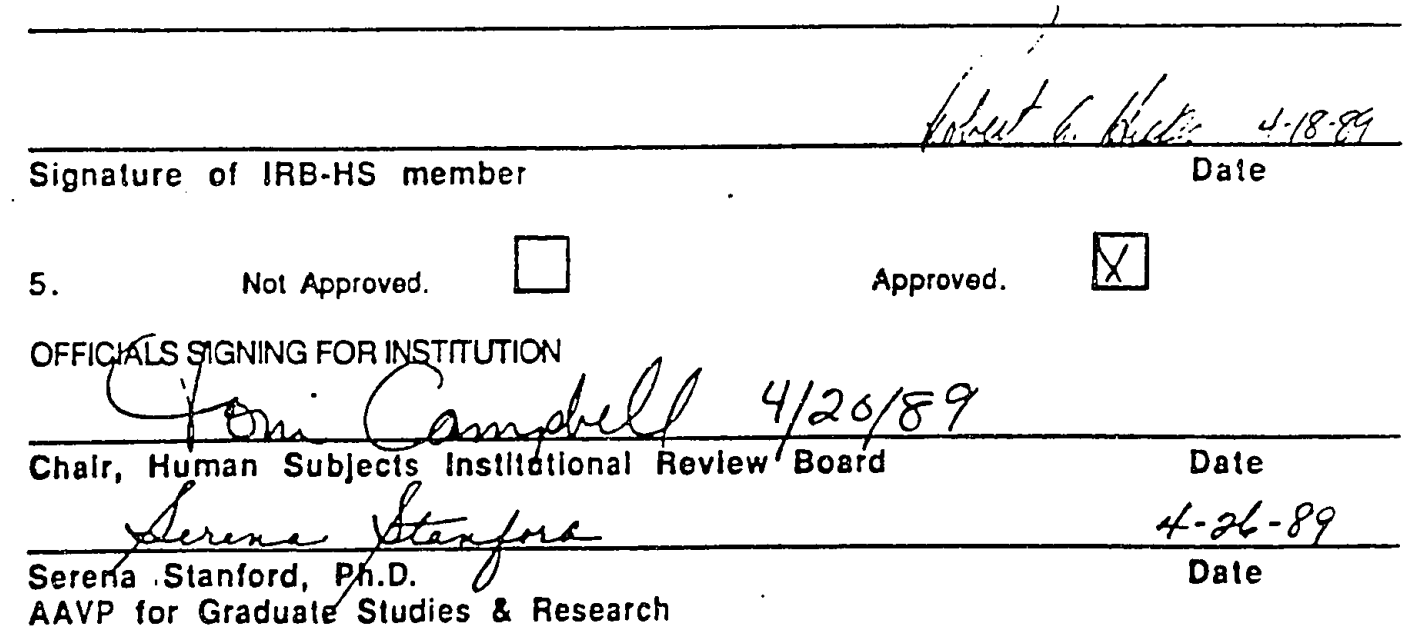

Please return to: San Jose Slate University Foundation, One Washinglon Square, San Jose, CA 95192.0139 (408) $924-1438$ 
APPENDIX C

Approval by Hospital Institutional Review Comittee 
PROFESSIONAL STAFF

March 13, 1989

Diane Bowers, R.N.

Education and Training Department

RE: THE EFFECTS OF THERAPEUTIC TOUCH ON STATE ANXIETY AND PHYSIOLOGICAL MEASUREMENTS IN PRE-OPERATIVE CLIENTS.

Dear Ms. Bowers:

Thank you for the presentation of the above listed study at the Institutional Review Committee on March 9, 1989.

Upon review of the study, the committee has unanimously voted for approval pending change in the investigator name to Diane Bowers. The Committee also requested that physicians that agree to work with Diane Bowers should receive a copy of the study.

As a condition of this approval it will be necessary for you to submit to the committee a written progress report/summary on an annual basis if you continue the use of this study.

Sincerely,

Chairman, Institutional Review Committee

FM: ia 
APPENDIX D

Physician Consent 
PHYSICIAN CONSENT FORM

page 1 of 2

Dear Dr.

As part of completing my master's thesis through the department of nursing at San Jose state University. I am conducting a quasi-experimental clinical study which will need to be approved by the IRC at the hospital and the Human Subjects comittee at San Jose State University. This letter is to notify you that I am interested in using your patients as possible subjects in the study, and request your consent for the patient's participation in the study.

The study will examine the effects of Therapeutic Touch on state anxiety and physiologic factors of blood pressure. pulse rate, respiratory rate, and peripheral skin temperature on surgical candidates. On the morning of your patient's scheduled surgery, I will be asking him or her to arsive before the surgery and fill out the self-Evaluation Questionnaire developed by Charles D. Spielberger, and will take blood pressure, pulse rate, respiratory rate, and skin temperature. Following a 5 minute session of Therapeutic Touch, the tests will be repeated. There will be not anticipated costs or discomforts imposed on the patient. One of the beseficial effects of the study may resilt in 
page 2 of 2

your patient feeling relaxed, caim, less tense, or drowsy. On rare occasions, recipients of Therapeutic Touch have felt a headache, or dizzy, particularly if they did not wish to have the treatment. If you have further questions, please contact Diane Bowers at the Hospital, 999-9999, Monday through Friday. Please return this form to me immediately in the enclosed envelope.

YOUR SIGNATURE BELOW INDICATES THAT YOU HAVE DECIDED THAT YOUR PATIENTS MAY PARTICIPATE IN THE STUDY SO LONG AS HE OR SHE AGREES TO DO SO. 
APPENDIX E

Client Pre-Requisite Data Form 
CLIENT PRE-REQUISITE DATA FORM

Researcher will determine the following:

1. Name

2. Address

3. Telephone number(s)

4. Age

5. Sex

6. Type of surgery

7. Type of anesthesia

8. Date of surgery

8. Surgeon's name

10. Physician's name

The Second Assistant will ask each client the following:

11. Primary language spoken:

12. According to what advice of the physician, did you make the decision to procoed with this surgery? (determines if surgery is due to life-threatening situation)

13. Are you willing to participate in the Therapeutic Touch treatment for as approzimate thirty minute period on the day of and prior to your scheduled surgery?

14. Are you currently practicing, or have you, within the past year practiced (more than a total of three times), either meditation and/or relaxation techniques such as visualization, guided imagery, grounding, or self-hypnosis? 


\section{APPENDIX $\mathbf{F}$ \\ Client Consent and \\ Experimental Subject's Bill of Rights}


page 1 of 4

\author{
AGREEMENT TO PARTICIPATE IN RESEARCH \\ AT SAN JOSE STATE UNIVERSITY \\ RESPONSIBLE INVESTIGATOR: DIANE BOWERS
}

\begin{abstract}
You are invited to participate in a study in which I hope to learn how Therapeutic Touch affects anxiety and changes in blood pressure, pulse, breathing rate, and peripheral skin temperature before surgery. You were selected as a possible participant in the study because you are scheduled for surgery to be performed at the hospital on
\end{abstract}

If you decide to participate. I will ask you to fill out a short 20 item questionnaire which measures anxiety, have your blood pressure, pulse rate, and breaching rate taken, and have a thermistor instrument placed on the middle finger of your left hand to measure your skin temperature. You will then receive either a Therapeutic Touch healing session or a session which mimicks Therapeutic Touch. With this procedure, you will sit quietly in a chair for 5 minutes while a the person administering the technique moves her hands around the perimeter of your body without touching you. The purpose of this procedure is to intentionally direct areas of tension in your body away from you. You may 
page 2 of 4

feel relaxed, calm, or drowsy, or experience a release of tension from your body. While side effects are extremely rare, some recipients have felt dizgy or lightheaded. Though Therapeutic Touch is considered to be a bealing modality, I cannot and do not guarantee or promise that you will receive any benefits from serving as a subject in this study.

Any information that is obtained in connection with this study, and that can be identified with you, will remain confidential and will be disclosed only with your permission or as required by law. Your participation is entirely voluntary and you may withäraw from the study at any ime. If you give me your permission by signing this document, I plan to disclose the total results of the larger study in the form of a master's thesis through the department of nursing at San Jose state University. The general results will be available to you upon request.

No compensation will be provided to you for participation in the study nor will any additional costs be charged to you. 
page 3 of 4

This project has been approved by the Institutional Review Board at the hospital and the Human subjects Review Board at San Jose State University. Your decision whether or not to participate will not prejudice your future relations witb the hospital or san Jose state University. If you decide to participate, you are free to withdraw your consent and to discontinue participation at any time without prejudice.

Any questions about your participation in the study will be answered by Diane Bowers (999) 999-9999. Ms. Bowers will be contacting you by phone to set up the time and location for the therapeutic touch treatment. If you are not satisfied with the manner in which this study is being conducted, you may report (anonymously, if you so choose) any complaints to the staff of the Review Committee by calling the hospital or by addressing a letter to the Chairman of the IRC at the hospital . 
page 4 of 4

\section{PAIIENT'S}

NAME

\section{PATIENT'S}

SIGNATURE DATE

Patient: Your signature on this informed consent form indicates that you have read and understand the information provided in this form, that you have had a chance to ask questions, that you bave decided to participate, and that you consent to the procedures or treatment described.

HITNESS DATE

Witness: Your signature indicates only that you have witnessed the signature of the patient. It does not imply that you are giving information regarding the investigational procedure, drug, or device to be studied. DATE

Investigator: The above signed (Diane Bowers, R.N., principal investigator) hereby certifies that she has discussed the research project with the participant and has explained all of the information contained in the informed consent form to the participant, including any adverse reactions that may reasonably be expected to occur. The above signed further certifies that the participant was encouraged to ask questions and that all questions were answered. 


\section{EXPERIMENTAL SUBJECT'S BLL OF RIGHTS}

The rights below are the rights of every person who is asked to in a research audy. As an experimental oubject thave the following righta:

1) To be told what the sludy is trying to find out.

2) To be told what will heppen to me and whether any of the proce. dures, drugs, of devices is different from what would be wed in anderd practice.

3) To rold abous the frequent and/or important riks, side effects or discomforts of the things that will heppen so we for revearch purposes,

4) To be told if 1 can expect any benefit from participating and, if $\infty$, what the benefit might be,

5) To be told the other choices I have and how they way be better or wore than being in the study,

6) To be allowed to ak any questions conceming the study bath be. tore epeering to be involved and during the coure of the study,

7) To be told what cont of ecdical trealment in avaliable if any compli. astions ariee,

8) To refue to participate at all or to chenge my mind about pertici. pation after the tudy is started. This decivion will not affect my right to receive the care I would receive if I were not in the atudy.

9) To receive a cupy of the signed and dated concent form, 10) To be tree of prewure when considering whether 1 wish to agree to
be in the otudy. 


\section{APPENDIX G}

Therapeutic Touch Practitioner Self-Inventory 
THERAPEUTIC TOUCH PRACTITIONER SELF-INVENTORY

Least Most

1. I felt grounded or centered during this trextment. $\quad 1 \quad 32 \quad 3 \quad 4 \quad 5$

2. I felt a bond or communication with the client. $\quad 1 \quad 2 \quad 3 \quad 4 \quad 5$

3. I noticed (felt, sensed) energy change during this treatment. $\quad \begin{array}{llllll} & 1 & 2 & 3 & 4 & 5\end{array}$ Describe

4. Did the client look or act differently after the treatment? Yes___ No If so, how? 